\title{
ANALISIS SISTEM TANGGAP DARURAT TUMPAHAN B3 STUDI KASUS DI PERUSAHAAN MANUFAKTUR
}

\author{
MOCHAMAD ULWAN PASHA, JULI SOEMIRAT, M CANDRA NUGRAHA DENI,
}

\author{
Program Studi Teknik Lingkungan, Fakultas Teknik Sipil dan Perencanaan \\ Institut Teknologi Nasional Bandung \\ Email : ulwanpasha@gmail.com
}

\begin{abstract}
ABSTRAK
Industri semakin banyak menggunakan material dan proses yang tergolong berbahaya yang dikelompokan sebagai bahan berbahaya dan beracun (B3). Setiap proses produksi memiliki risiko terjadinya kecelakaan kerja yang diakibatkan oleh B3 hingga mengakibatkan keadaan darurat yang dapat merugikan secara kesehatan, material, dan finansial. PT X merupakan perusahaan yang bergerak di bidang manufaktur, dengan terdapat 5 proses produksi diantara nya: gudang penyimpanan barang produksi, konstruksi, nailing, assembling, dan finishing. Dalam tahap tersebut terdapat B3 seperti nikel, chromium, asam sulfat, dan solar yang digunakan. Oleh karena itu, perlu dilakukan evaluasi sistem tanggap darurat tumpahan B3 pada PT $X$, yang terdiri dari manajemen tanggap darurat, sarana dan prasarana tanggap darurat, dan pengelolaan B3 itu sendiri. Evaluasi dilakukan dengan membandingkan kondisi eksisting dengan peraturan diantaranya PermenLHK 74/2019, PermenLH 03/2008, dan beberapa National fire protection association (NFPA). Hasil evaluasi menunjukan nilai penerapan sistem tanggap darurat B3 di PT X sebesar 49,82\% dikarenakan terdapat beberapa komponen yang belum tersedia dan beberapa komponen yang tidak sesuai standar. Oleh karena itu diperlukan suatu sistem tanggap darurat tumpahan B3 berupa rencana pengelolaan kedaruratan (RPK), mulai dari merencanakan tindakan pencegahan tumpahan, tindakan pada saat terjadi tumpahan, hingga pada pemulihan pasca tumpahan B3.
\end{abstract}

Kata kunci: Industri, B3, Sistem Tanggap Darurat, rencana pengelolaan kedaruratan

\begin{abstract}
Hazardous chemicals are substances that are classified known as hazardous substances. Production processes using such substances may carry a risk of work accidents caused by them resulting in emergencies that can be detrimental to health, and cause material, and financial losses. PT X is a manufacturing company, with 5 production processes i.e: warehouse storage of production, construction, nailing, assembling, and finishing, where hazardous materials such as nickel, chromium, sulfuric acid, and diesel are being used. Evaluation of hazardous materials spill emergency response system at PT X consisting of emergency response management, facilities and infrastructure, and proper management were conducted by comparing existing conditions with regulations including PermenLHK 74/2019, PermenLH 03/2008, and several National fire protection associations. The results showed that the implementation of these hazardous materials emergency response system at PT X only comply for 49.82\% due to lack of some components and some were not in accordance with the exisiting standards. Hence the need for a comprehensive hazardous materials emergency response system in the form of an emergency management plan, starting from planning spill prevention measures, taking action in the event of a spillage to post hazardous materials spill recovery.
\end{abstract}

Keywords: Industry, Hazardous Materials, Emergency Response, Emergency Management Plan 


\section{PENDAHULUAN}

Pembangunan erat kaitannya dengan kegiatan di sektor industri, dan guna mengikuti perkembangan zaman, setiap perusahaan akan meningkatkan mutu, produktivitas, dan efektivitas kerja. Seiring dengan meningkatnya penggunaan teknologi pada suatu industri modern, maka efisiensi produksi kian bertambah. Salah satu faktor penting dalam meningkatnya efisiensi produksi, yaitu dengan menggunakan B3 sebagai bahan baku ataupun bahan penunjang proses produksi. Akan tetapi, penggunaan B3 memiliki potensi risiko yang lebih besar terjadinya kecelakaan kerja. Penggunaan atau penanganan B3 dan/atau limbah B3 akan menimbulkan potensi keadaan darurat yang dapat mengakibatkan kerugian, baik secara materil maupun non materil.

B3 merupakan material yang memiliki karakteristik mudah terbakar, mudah meledak, korosif, radioaktif, infektif, toksik, mutagenik, karsinogenik, teratogenik, reaktif, dapat menyebabkan defisiensi oksigen dan campuran dari berbagai karakteristik (PermenLH 03, 2008). Material B3 perlu menjadi perhatian besar karena berpotensi menimbulkan keadaan darurat yang berdampak pada pekerja serta masyarakat di sekitarnya. Keadaan darurat yaitu kejadian mendadak hingga menyebabkan banyak korban kematian atau cedera pada pekerja dan masyarakat atau suatu keadaan yang menggangu dan menghentikan proses industri, perdagangan, dan menyebabkan kerusakan lingkungan (Salami,2015). Contohnya adalah tumpahan B3 dengan volume besar dan sulit dikendalikan akibat kebocoran wadah atau kemasan penampung atau penyimpan. Kondisi seperti itu mewajibkan industri melakukan penanggulangan yang tepat sesuai dengan prosedur standar yang berlaku. Untuk mengantisipasi dampak yang terjadi dari kecelakaan seperti ini, perusahaan perlu untuk memiliki sistem pengelolaan kedaruratan.

PT. X merupakan perusahaan yang bergerak dibidang manufaktur, yang berdiri pada awal tahun 1979 dan beroperasi pada tahun 1981. Jumlah karyawan yang bekerja di PT. X sebanyak 550 orang. Secara umum, perusahaan ini memproduksi 3 macam produk, yaitu kursi, tempat tidur rumah sakit, dan peralatan kantor. Kegiatan produksi terbagi menjadi 5 bagian, yaitu gudang penyimpanan barang produksi, konstruksi, nailing, assembling, dan finishing. Pada tahapan produksi di PT. X menggunakan beberapa B3, seperti nikel, chromium trioxide, asam sulfat, dan solar.

Keputusan Menteri Tenaga Kerja Republik Indonesia Nomor 187 Tahun 1999 tentang Pengendalian Bahan Kimia Berbahaya di Tempat Kerja, menyatakan bahwa untuk mencegah kecelakaan dan penyakit kerja akibat bahan kimia berbahaya, maka perlu diatur pengendaliannya. Selain itu, juga berguna untuk menjaga aset-aset yang dimiliki perusahaan, termasuk menjaga serta mencegah pencemaran lingkungan sekitar yang dapat merugikan banyak pihak. Oleh sebab itu diperlukan evaluasi penerapan sistem tanggap darurat tumpahan bahan berbahaya berbentuk padat dan/atau cair di PT. X.

\section{BAHAN DAN METODE}

Penelitian ini dilakukan di PT X yang menggunakan B3, seperti Nikel (Ni), Chromium trioxide (Cr) Asam Sulfat, dan Solar dalam proses pelapisan logamnya. Pada tahun 2016, PT X pernah mengalami kecelakaan berupa tumpahan solar yang mengalir pada saluran drainase dan pada tahun 2019 terjadi rembesan nikel pada bagian produksi sehingga menghentikan aktivitas produksi perusahaan. Berdasarkan pengalaman tersebut dan potensi risiko yang ada, maka diperlukan suatu sistem tanggap darurat berupa Rencana Pengelolaan 
Kedaruratan (RPK) yang bertujuan untuk melindungi pekerja, masyarakat, properti, serta lingkungan dari dampak yang dihasilkan oleh situasi bahaya (Salami, 2015).

Penelitian dilakukan secara kualitatif dengan melakukan observasi dan wawancara secara langsung pada pihak PT $X$. Evaluasi penerapan sistem tanggap darurat dilakukan berdasarkan observasi di 5 (lima) area produksi. Pengumpulan data yang dilakukan dengan menggunakan metode checklist pada komponen yang wajib tersedia, yang selanjutnya akan dibandingkan dengan standar di bawah ini:

* PermenLHK No. 74 Tahun 2019;

* Keputusan Menteri Tenaga Kerja Republik Indonesia Nomor 187 Tahun 1999;

* NFPA 72, NFPA 10, dan NFPA 101;

* Permenakertrans No. 08 Tahun 2010;

* Ansi z358.1-2004;

* Permenakertrans No. 15 Tahun 2008;

* Permen PU No. 26 Tahun 2008;

* Material Safety Data Sheet (MSDS);

* PermenLH No. 03 Tahun 2008.

Setelah dilakukan evaluasi terhadap penerapan sistem tanggap darurat tumpahan B3 di PT. $X$, kemudian dilakukan penilaian tingkat kesesuaian berdasarkan metode likert dengan penilaian seperti berikut:

Tabel 1. Penilaian Eksisting Terhadap Standar

\begin{tabular}{cll}
\hline Nilai & \multicolumn{1}{c}{ Parameter } & \multicolumn{1}{c}{ Keterangan } \\
\hline $\mathbf{0}$ & Tidak Ada & Jika tidak terdapat komponen \\
\hline $\mathbf{1}$ & Tidak Sesuai & $\begin{array}{l}\text { Jika terdapat komponen tapi belum } \\
\text { memenuhi standar }\end{array}$ \\
\hline $\mathbf{2}$ & Kurang Sesuai & $\begin{array}{l}\text { Jika terdapat beberapa komponen tapi } \\
\text { belum memenuhi standar }\end{array}$ \\
\hline $\mathbf{3}$ & Cukup Sesuai & $\begin{array}{l}\text { Jika terdapat komponen tapi beberapa } \\
\text { sudah memenuhi standar }\end{array}$ \\
\hline $\mathbf{4}$ & Sesuai & $\begin{array}{l}\text { Jika terdapat seluruh komponen dan } \\
\text { memenuhi standar }\end{array}$ \\
\hline
\end{tabular}

Sumber: Hasil Analisis, 2019

\section{HASIL DAN PEMBAHASAN}

\subsection{Identifikasi Proses Berbahaya}

PT. X memiliki 5 unit kerja utama yang meliputi proses konstruksi, yang mana dibutuhkan bahan oli mesin dan larutan coolant untuk melakukan pelubangan serta pada tahap ini juga terjadi pengelasan pada tekukan pipa agar saling menyambung satu sama lain.

Selanjutnya pada proses nailing dilakukan perakitan bagian cover jok atau kasur, dimana pada tahap ini dilakukan pengeleman pada bagian busa dan kain jok dengan metode penyemprotan.

Pada proses finishing pengerjaan operasional dilakukan selama 24 jam, dan digunakan 4 (empat) jenis B3 yaitu asam sulfat, chromium trioxide, nikel, dan solar.

Pada proses assembling, yang merupakan tahap terakhir, dilakukan perakitan setiap komponen utama yang telah dibentuk dengan aksesoris lainya seperti busa, sandaran, label dan merk menjadi sebuah kursi, meja ataupan tempat tidur rumah sakit yang siap dikemas dan kemudian dipasarkan. Serta area gudang yang digunakan untuk menyimpan bahan mentah yang akan diproses. 


\subsection{Identifikasi B3 di PT. X}

Identifikasi material berbahaya dilakukan berdasarkan Material Safety Data Sheet (MSDS) dan PermenLH No. 03 Tahun 2008 tentang Tata Cara Pemberian Simbol dan Label B3. Dari hasil identifikasi proses berbahaya, diketahui bahwa pada proses finishing terdapat 4 jenis B3 yang merupakan bahan utama dengan kuantitas pemakaian tergolong tinggi serta berpotensi memiliki dampak yang berbahaya bagi karyawan, masyarakat, bahkan lingkungan sekitar. Pemakaian B3 pada PT X pada periode 2019 untuk nikel sebanyak 31.160 kg, chromium trioxide sebanyak $6.750 \mathrm{~kg}$, asam sulfat $24.422 \mathrm{~kg}$, dan solar sebanyak 85.665 liter. Nikel bersifat korosif, karsinogenik, teratogenik, dan mutagenik. Chromium trioxide bersifat karsinogenik, teratogenik, mutagenik, beracun, korosif, berbahaya bagi lingkungan, dan pengoksidasi. Asam sulfat bersifat korosif, sedangkan solar bersifat mudah menyala, irritant, karsinogenik, teratogenik, dan mutagenik. Berdasarkan Keputusan Menteri Tenaga Kerja Republik Indonesi No. 187/1999, maka dapat disimpulkan PT X dapat dikatagorikan sebagai perusahaan yang mempunyai potensi bahaya menengah dan wajib menyusun program kedaruratan B3.

\subsection{Program Kedaruratan Pengelolaan B3 dan/atau Limbah B3}

Berdasarkan PermenLHK No. 74 Tahun 2019, PT. X wajib menyusun program kedaruratan B3, karena menggunakan B3 yang mempunyai potensi bahaya menengah. Berdasarkan hasil penilaian kesesuaian antara kondisi saat ini dan kriteria pada peraturan PermenLHK No. 74 Tahun 2019, nilai kesesuaian manajemen tanggap darurat B3 di PT. X yang masih $16,67 \%$, seperti yang ditunjukkan pada Tabel 2.

Tabel 2. Rata-rata Kesesuaian Manajemen Tanggap Darurat di PT. $X$

\begin{tabular}{rcc}
\hline No. & Bagian & Nilai Kesesuaian \\
\hline $\mathbf{1}$ & Organisasi Tanggap Darurat & $0 \%$ \\
\hline $\mathbf{2}$ & Prosedur Tanggap Darurat & $50 \%$ \\
\hline $\mathbf{3}$ & Pelatihan Tanggap Darurat & $0 \%$ \\
\hline \multicolumn{2}{c}{ Rata-Rata } & $\mathbf{1 6 , 6 7} \%$ \\
\hline
\end{tabular}

Sumber: Hasil Penelitian, 2019

Tingkat kesesuaian organisasi tanggap darurat sebesar $0 \%$ dikarenakan belum tersedia organisasi tanggap darurat di PT. X. Keberadaan organisasi sangat dibutuhkan ketika terjadinya kedaruratan agar koordinasi serta tugas dan fungsi setiap karyawan menjadi lebih tanggap dan jelas dalam mengatasi dampak yang ditimbulkan. Hasil evaluasi terhadap prosedur tanggap darurat menunjukan nilai $50 \%$ dikarenakan prosedur penanganan tumpahan B3 telah tersedia akan tetapi prosedur yang ada belum mencantuman secara detail mengenai B3 yang digunakan. Untuk pelatihan tanggap darurat menunjukan tingkat kesesuaian sebesar $0 \%$ karena PT. $\mathrm{X}$ belum pernah melakukan pelatihan tanggap darurat tumpahan B3.

\subsection{Evaluasi Sarana dan Prasarana}

Sarana fasilitas kedaruratan diperlukan untuk mengendalikan keadaan darurat yang sedang terjadi, sehingga dampak serta kerugian yang ditimbulkan dapat diminimalisir. Sarana ini meliputi fasilitas pusat kendali darurat, alarm kedaruratan, sistem peringatan kepada publik, serta peralatan kedaruratan seperti kendaraan darurat, alat pernafasan, peralatan pemadam kebakaran, peralatan pengurungan, agen penetralisir, peralatan pertolongan pertama, dan lokasi isolasi bebas listrik, gas dan uap (SAW, 2012). Berdasarkan hasil penilaian kesesuaian antara kondisi saat ini dengan peraturan terkait, tingkat kesesuaian sarana dan prasarana pada masing-masing bagian produksi tertera pada Tabel 3. 
Tabel 3. Rata-rata Kesesuaian Sarana dan Prasarana di PT. $X$

\begin{tabular}{|c|c|c|c|c|c|c|c|}
\hline No & Komponen & $\begin{array}{c}\text { Gudang } \\
\text { Penyimpanan } \\
\text { Bahan }\end{array}$ & Konstruksi & Nailing & Finishing & Assembling & Rata-rata \\
\hline 1 & Alarm & $0 \%$ & $0 \%$ & $0 \%$ & $0 \%$ & $100 \%$ & $20 \%$ \\
\hline 2 & $\begin{array}{l}\text { Alat Pemadam } \\
\text { Api Ringan } \\
\text { (APAR) }\end{array}$ & $96,87 \%$ & $98,43 \%$ & $98,43 \%$ & $98,43 \%$ & $98,43 \%$ & $98,11 \%$ \\
\hline 3 & $\begin{array}{l}\text { Alat Pelindung } \\
\text { Diri }\end{array}$ & $83,33 \%$ & $83,33 \%$ & $83,33 \%$ & $83,33 \%$ & $83,33 \%$ & $83,33 \%$ \\
\hline 4 & $\begin{array}{l}\text { Emergency } \\
\text { Shower }\end{array}$ & $79,16 \%$ & $79,16 \%$ & $79,16 \%$ & $79,16 \%$ & $79,16 \%$ & $79,16 \%$ \\
\hline 5 & Fasilitas P3K & $80 \%$ & $80 \%$ & $80 \%$ & $80 \%$ & $80 \%$ & $80 \%$ \\
\hline 6 & Kotak P3K & $80 \%$ & $85 \%$ & $85 \%$ & $85 \%$ & $85 \%$ & $84 \%$ \\
\hline 7 & Isi Kotak P3K & $5 \%$ & $5 \%$ & $5 \%$ & $5 \%$ & $5 \%$ & $5 \%$ \\
\hline 8 & $\begin{array}{l}\text { Petunjuk arah } \\
\text { jalan keluar }\end{array}$ & $82,14 \%$ & $82,14 \%$ & $82,14 \%$ & $82,14 \%$ & $82,14 \%$ & $82,14 \%$ \\
\hline 9 & $\begin{array}{l}\text { Tempat } \\
\text { berkumpul } \\
\text { sementara }\end{array}$ & $100 \%$ & $100 \%$ & $100 \%$ & $100 \%$ & $100 \%$ & $100 \%$ \\
\hline 10 & $\begin{array}{l}\text { Alat Komunikasi } \\
\text { Darurat }\end{array}$ & $100 \%$ & $100 \%$ & $100 \%$ & $100 \%$ & $100 \%$ & $100 \%$ \\
\hline 11 & $\begin{array}{l}\text { Pusat kontrol } \\
\text { darurat }\end{array}$ & $0 \%$ & $0 \%$ & $0 \%$ & $0 \%$ & $0 \%$ & $0 \%$ \\
\hline 12 & Windsock & $0 \%$ & $0 \%$ & $0 \%$ & $0 \%$ & $0 \%$ & $0 \%$ \\
\hline 13 & $\begin{array}{l}\text { Peralatan } \\
\text { pengurungan }\end{array}$ & $0 \%$ & $0 \%$ & $0 \%$ & $0 \%$ & $0 \%$ & $0 \%$ \\
\hline 14 & $\begin{array}{l}\text { Agen } \\
\text { Penetralisir }\end{array}$ & $0 \%$ & $0 \%$ & $0 \%$ & $0 \%$ & $0 \%$ & $0 \%$ \\
\hline
\end{tabular}

Rata-rata Tingkat Pemenuhan

Sumber: Hasil Penelitian, 2019

Tingkat kesesuaian untuk komponen dengan nilai 100\% menunjukkan bahwa komponen telah sesuai dengan peraturan yang digunakan, seperti pada adanya 'tempat berkumpul sementara' dan 'alat komunikasi darurat'. Tingkat kesesuaian komponen 'alarm' menunjukan nilai $0 \%$ karena tidak tersedianya sistem alarm pada area gudang penyimpanan bahan, konstruksi, nailing dan finishing. Hasil observasi lapangan menunjukan ketidaksesuaian komponen 'APAR' dengan peraturan, karena terdapat satu temuan pada bagian gudang yaitu APAR terhalangi oleh benda lain, sedangkan untuk penilaian lain berdasarkan NFPA 10, APAR yang berada diluar ruangan diharuskan menggunakan lemari tidak terkunci, yang belum terpenuhi oleh PT. X. Tingkat kesesuaian untuk komponen 'APD' dengan peraturan yang berlaku pada 5 area yang ada sebesar 83,33\%, pemberian nilai kurang baik diberikan pada parameter pelaksanaan manajemen APD, hal ini dikarenakan penerapannya belum sesuai dengan peraturan yang berlaku, seperti belum dilaksanakannya perawatan, pembinaan, dan inspeksi. Untuk komponen 'emergency shower', terdapat ketidaksesuaian dengan standar yaitu penempatannya yang cukup jauh dari area produksi, dan inspeksi tidak dilakukan setiap 1 minggu sekali. Pada komponen 'fasilitas P3K' hampir semua standar telah terpenuhi, kecuali pada alat transportasi medis perusahaan yang belum tersedia. Untuk tingkat ratarata nilai kesesuaian komponen 'kotak $\mathrm{P} 3 \mathrm{~K}^{\prime}$ diperoleh nilai sebesar 84\%, karena terdapat ketidaksesuaian pada isi kotak P3K, sedangkan komponen 'isi kotak P3K' nilai yang didapatkan sebesar 5\%, karena hanya terdapat obat tetes mata dan betadine. 
Juga terdapat ketidaksesuaian untuk komponen 'petunjuk arah jalan keluar' dimana tidak terdapat sumber iluminasi darurat. Sedangkan untuk komponen 'pusat kontrol darurat', 'windsock', peralatan pengurungan' dan 'agen penetralisir' belum tersedia di PT. X sehingga tingkat kesesuaian dengan peraturan sebesar $0 \%$.

\subsection{Evaluasi Pengelolaan B3}

Evaluasi pengelolaan B3 merupakan kelanjutan dari tahap identifikasi dan tahap evaluasi sarana dan prasarana. Pengelolaan B3 perlu dilakukan sesuai dengan pedoman penyimpanan dan peraturan pelabelan mengenai B3. Tingkat kesesuaian pengelolaan B3 yang tertera pada Tabel 4.

Tabel 4. Rata-rata Nilai Pengelolaan B3 di PT. $X$

\begin{tabular}{clcccc}
\hline No & $\begin{array}{c}\text { Komponen } \\
\text { Pengelolaan B3 }\end{array}$ & $\begin{array}{c}\text { Bahan Berbahaya dan Beracun } \\
\text { Chromium } \\
\text { Trioxide }\end{array}$ & Nikel & $\begin{array}{c}\text { Asam } \\
\text { Sulfat }\end{array}$ & Solar \\
\hline $\mathbf{1}$ & Penyimpanan B3 & $100 \%$ & $100 \%$ & $100 \%$ & $100 \%$ \\
\hline $\mathbf{2}$ & $\begin{array}{l}\text { Simbol dalam kemasan } \\
\text { B3 }\end{array}$ & $80 \%$ & $80 \%$ & $80 \%$ & $80 \%$ \\
\hline $\mathbf{3}$ & $\begin{array}{l}\text { Simbol pada tempat } \\
\text { penyimpanan B3 }\end{array}$ & $0 \%$ & $0 \%$ & $93,75 \%$ & $100 \%$ \\
\hline $\mathbf{4}$ & $\begin{array}{l}\text { Label pada } \\
\text { penyimpanan B3 }\end{array}$ & $91,67 \%$ & $91,67 \%$ & $100 \%$ & $100 \%$ \\
\hline & Rata - rata & $\mathbf{6 7 , 9 1 \%}$ & $\mathbf{6 7 , 9 1 \%}$ & $\mathbf{9 1 , 3 5 \%}$ & $\mathbf{9 5 \%}$ \\
\hline
\end{tabular}

Sumber: Hasil Analisis, 2019

Tabel 4. menunjukan perlu adanya perbaikan pengelolaan B3 dalam penggunaan simbol pada tempat penyimpanan B3 yang bertujuan untuk menginformasikan bahaya yang dapat ditimbulkan pada area sekitar penyimpanan B3. Nilai yang didapatkan dari pengelolaan B3 di PT. $X$ sebesar $80,54 \%$ berdasarkan komponen penyimpanan B3, simbol dalam kemasan B3, simbol pada tempat penyimpanan B3, dan label pada penyimpanan B3.

\subsection{Rekapitulasi Nilai Akhir Sistem Tanggap Darurat Tumpahan B3 di PT. X}

Rekapitulasi nilai akhir sistem tanggap darurat tumpahan B3 adalah seperti ditunjukkan pada Tabel 5.

Tabel 5. Rekapitulasi Nilai Akhir Sistem Tanggap Darurat Tumpahan B3 di PT. X

\begin{tabular}{clc}
\hline No & Kriteria Penilaian & Nilai Kesesuaian \\
\hline $\mathbf{1}$ & Manajemen Tanggap Darurat & $16,67 \%$ \\
\hline $\mathbf{2}$ & Sarana dan Prasarana & $52,26 \%$ \\
\hline $\mathbf{3}$ & Pengelolaan B3 & $80,54 \%$ \\
\hline \multicolumn{2}{c}{ Rata - rata } & $\mathbf{4 9 , 8 2 \%}$ \\
\hline
\end{tabular}

Tabel 5 menunjukan nilai rata-rata kesesuaian sistem tanggap darurat tumpahan B3 di PT. X sebesar $49,82 \%$. Penilaian tersebut didapatkan dengan cara menjumlahkan hasil akhir dari setiap kriteria yang kemudian dibagi dengan jumlah kriteria sehingga didapatkan nilai ratarata. Dengan nilai kesesuaian manajemen tanggap darurat yang relatif kecil, maka diperlukan pembentukan manajemen yang terstruktur serta jelas secara tugas, pokok, dan fungsi guna memperbaiki sistem yang tersedia, untuk mengurangi risiko kedaruratan yang 
disebabkan oleh B3. Manajemen yang baik akan membuat nilai kesesuaian sarana dan prasarana serta pengelolaan B3 akan meningkat.

\subsection{Rencana Pengelolaan Kedaruratan (RPK) Tumpahan B3}

Program Kedaruratan Pengelolaan B3 dan/atau Limbah B3 adalah dokumen perencanaan sistem tanggap darurat yang memiliki komponen infrastruktur dan fungsi penanggulangan. RPK memuat 4 poin penting, yaitu jenis keadaan darurat, fasilitas gawat darurat, organisasi tanggap darurat, fasilitas di sekitar area perusahaan, dan standar operasional prosedur kedaruratan.

\subsubsection{Jenis Keadaan Darurat}

Berdasarkan identifikasi keadaan darurat dalam lingkungan kerja, PT. X menunjukan keadaan darurat yang belum terproteksi yaitu tumpahan B3.

\subsubsection{Fasilitas Gawat Darurat}

Beberapa instansi yang berkerjasama dalam upaya pengelolaan kedaruratan di PT. X, diantaranya Dinas Lingkungan Hidup (DLH) Kota Cimahi, Satuan Polisi Pamong Praja dan Pemadam Kebakaran, Rumah Sakit Mitra Anugrah Lestari, Rumah Sakit Dustira, Rumah Sakit Umum Kasih Bunda, Kepolisian Sektor (Polsek) Pharmindo, serta Kepolisisan Resor Besar (Polrestabes) Kota Cimahi.

\subsubsection{Organisasi Tanggap Darurat}

Organisasi tanggap darurat yang dimuat di dalam RPK merupakan organisasi yang memiliki tugas dan fungsi dalam melaksanakan program kedaruratan Pengelolaan B3. Gambar 1. merupakan Rencana Struktur Organisasi Tanggap Darurat di PT. X. Personil yang terlibat ditetapkan langsung oleh direksi perusahaan dengan menunjuk personil yang berkompeten pada bidangnya.

\subsubsection{Fasilitas di Sekitar Area Perusahaan}

Fasilitas di sekitar area perusahaan PT. X penting untuk diketahui untuk memberikan peringatan serta antisipasi dampak yang akan ditimbulkan apabila terjadi keadaan darurat. Terdapat 4 perusahaan dengan radius 0,3 km dekat dengan PT. X, yaitu PT Berdikari Metal Engineering, PT. Sanlit Inlit Plastik, PT. Indo Pratama Plastik, dan PT. Fastrata Buana.

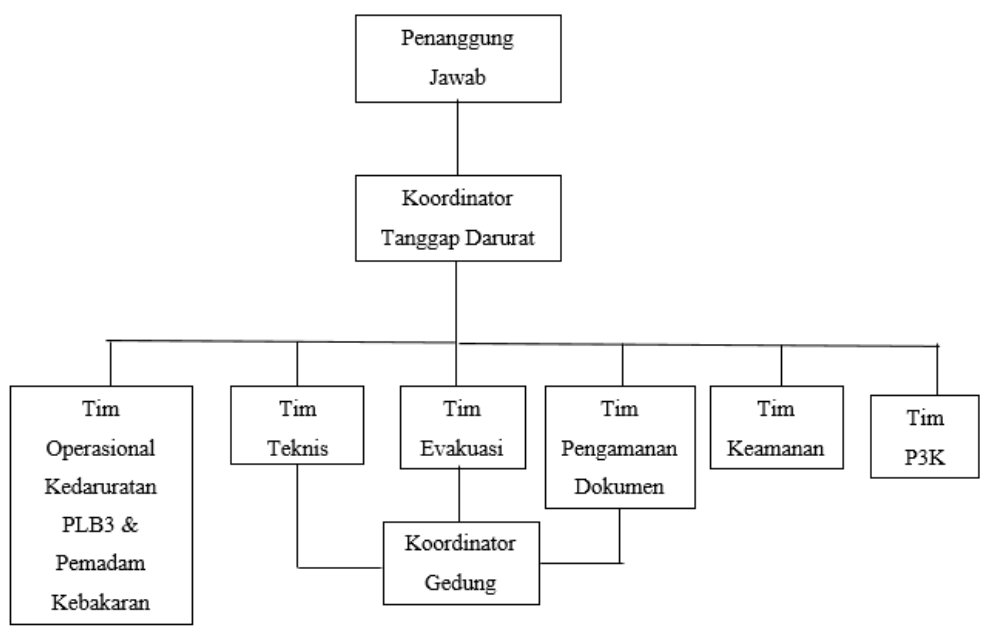

Gambar 1. Rencana Struktur Organisasi Tanggap Darurat PT X Sumber: Hasil Analisis 2020 


\subsubsection{Standar Operasional Prosedur (SOP) Kedaruratan}

SOP menjelaskan tahapan tindakan yang dapat dilakukan ketika menghadapi keadaaan darurat. SOP memuat beberapa hal penting, seperti pencegahan tumpahan, penanganan kesiagaan dan tanggap darurat, tindakan pencegahan bahaya, tata cara pertologan pertama, tata cara penanggulangan tumpahan, tata cara penanggulangan kebakaran, alat pelindung diri, evakuasi, prosedur penyelamatan, dan prosedur pemulihan kedaruratan.

\section{- Pencegahan Tumpahan}

Pencegahan tumpahan dilakukan untuk mengetahui potensi bahaya dari B3 dengan cara mengevaluasi B3 berdasarkan klasifikasi yang dimuat dalam MSDS. Dalam mencegah tumpahan di PT. X, maka diperlukan pekerja ahli B3 untuk mengevaluasi kecukupan tindakan pencegahan, kuantitas serta kualitas B3 yang sesuai dengan kebutuhan operasional, serta langkah-langkah darurat di dalam perusahaan.

\section{- Penanganan Kesiagaan dan Tanggap Darurat}

Dalam penanganan kesiagaan dan tanggap darurat perlu dilakukannya beberapa identifikasi, yaitu tempat atau jalur rawan darurat, pos polisi, regu pemadam kebakatan, pos kesehatan agar dapat menentukan jarak aman menuju lokasi evakuasi. Unit tanggap darurat bertugas untuk membuat mekanisme tahapan penanggulangan darurat (mandiri, gabungan, dan nasional) sesuai dengan prosedur handling B3, prosedur pembersihan lokasi/area yang terkontaminasi, serta prosedur pertolongan pertama.

\section{- Tindakan Pencegahan Bahaya}

Hal pertama yang harus dilakukan ketika terjadinya tumpahan untuk keempat jenis B3, yaitu segera isolasi area tumpahan/kebocoran setidaknya sejauh 50 meter ke seluruh arah (material cair B3); dan 25 meter ke seluruh arah (material padat B3). Saaat tumpahan terjadi, pihak yang tidak berwenang (selain petugas penanganan khusus B3) dilarang mendekati area yang terkontaminasi agar tidak terjadinya paparan. Hindari posisi berhadapan dengan arah angin berlawanan, serta jauhi area dengan ketinggian yang lebih rendah. Gunakan Alat Pelindung Diri (APD) berbahan khusus yang sesuai dengan karakteristik masing-masing jenis B3.

\section{- Tata Cara Pertolongan Pertama}

Saat tumpahan nikel di PT. X terjadi, maka tata cara pertolongan pertama yang harus dilakukan, yaitu memindahkan korban ke tempat terbuka, lepaskan dan isolasi pakaian yang terkontaminasi. Apabila tumpahan B3 kontak dengan mata dan kulit maka basuh area paparan korban dengan air yang mengalir selama 20 menit. Apabila B3 tertelan, maka segera mencuci mulut (kumur-kumur) menggunakan air bersih dan segera hubungi tenaga medis untuk penanganan lebih lanjut.

Tata cara pertolongan pertama apabila terkena paparan B3 chromium trioxide di PT. X, yaitu dengan memindahkan korban dan isolasi pakaian yang terkontaminasi. Apabila B3 kontak dengan kulit/mata, maka basuh dengan air mengalir selama 20 menit. Apabila B3 tidak sengaja tertelan, maka cuci mulut dan kumur kumur. Bila terhirup tempatkan di ruang terbuka dan segera bawa ke dokter. Untuk gejala lebih lanjut lebih baik menghubungi tenaga medis terdekat.

Tata cara pertolongan pertama apabila terkena paparan asam sulfat yaitu memindahkan korban menuju tempat terbuka dengan udara yang segar, berikan oksigen bila kesulitan bernafas. Segera isolasi pakaian dan sepatu yang terkontaminasi. Apabila B3 kontak dengan 
kulit/mata korban, untuk penanganan paparan pada kulit gunakan sodium karbonat $5 \%$, lalu basuh dengan air mengalir selama 20 menit. Apabila terjadi luka bakar, maka balut luka dengan kain kasa steril.

Langkah awal dalam melakukan pertolongan pertama ketika terjadi paparan tumpahan solar, yaitu pindahkan korban menuju tempat terbuka dengan udara segar dan segera hubungi petugas medis setempat. Berikan nafas buatan atau oksigen apabila korban sulit bernafas. Ketika Solar terkena kulit, basuh dengan air bersih selama 20 menit. Jika kulit terbakar, maka jangan lepaskan pakaian yang menempel pada kulit.

\section{- Tata Cara Penanggulangan Tumpahan}

Tata cara penanggulangan tumpahan bertujuan untuk meminimalisir dampak yang terjadi akibat tumpahan. Langkah-langkah Ketika terjadi tumpahan nikel, pertama segera menjauh dari area yang terkena tumpahan kemudian gunakan APD (kacamata pelindung, pakaian, sarung tangan berbahan butyl-rubber dan face shield). Singkirkan semua sumber api (rokok, suar, dan pemicu percikan api). Tumpahan Nikel dapat ditutupi dengan tanah kering atau pasir yang dilapisi plastik agar meminimalkan kontak dengan hujan. Pembersihan tumpahan dilakukan dengan memasukan limbah ke dalam kontainer kosong.

Ketika terjadi tumpahan chromium trioxide, maka langkah awal yang langsung dilakukan adalah menjauh dari area yang terkena tumpahan dan gunakan APD yang sesuai (kacamata pelindung, pakaian, sarung tangan berbahan butyl rubber dan face shield). Bila terjadi tumpaha kecil, maka gunakan vermiculite atau pasir untuk menyerap produk. Bila yang terjadi tumpahan besar, buatlah tanggul untuk menampung tumpahan dan vermiculite untuk menyerap produk. Hindari disperi debu akibat bahan yang ditutupi oleh pasir. Apabila serbuk bubuk terlepas ke udara kenakan respirator, lalu diperlukan evakuasi dari tempat berbahaya, serta tutup jendela dan pintu (untuk tempat berbahaya maupun tempat disekitarnya); Dilarang membersihkan dengan menggunakan kuas atau udara bertekanan apabila material berbentuk serbuk.

Ketika terjadi tumpahan Asam Sulfat, maka langkah awal yang harus dilakukan adalah segera menjauh dari area yang terkena tumpahan dan gunakan APD yang sesuai (kacamata pelinfung, pakaian, sarung tangan berbahan butyl-rubber dan face shield). Tandai area berbahaya, jauhkan dari bahan mudah terbakar (kayu, kertas, minyak, dll). Gunakan semprotan air untuk mengurangi uap, namun jangan arahkan air secara langsung dengan tumpahan. Tumpahan dapat ditutupi dengan tanah kering atau pasir, kemudian dilapisi plastik tertutup dan dimasukan ke dalam kontainer kosong. Hindari material masuk ke dalam saluran air pembuangan atau ruang bawah tanah.

Ketika terjadi tumpahan solar gunakan APD berbahan nitrile, neoprene atau PVC; Jangan menyentuh atau berjalan pada material yang tumpah; Apabila kondisi aman dan memungkinkan, hentikan kebocoran B3 dengan hati-hati; Jauhkan semua sumber api; Tutupi menggunakan pasir kering atau tanah kering; Tidak diperbolehkan untuk menyiram (flush) saluran pembuangan maupun drainase.

\section{- Tata Cara Penanggulangan Kebakaran}

Saat terjadi tumpahan nikel, maka diperlukan suatu tata cara penanggulangan kebakaran, menggunakan media pemadam seperti busa (foam), serbuk kering, karbon dioksida, semprotan air, serta pasir. Saat memadamkan api gunakan pelindung pernafasan serta APD berbahan khusus resisten terhadap bahan kimia dan api. 
Saat terjadi tumpahan chromium trioxide, maka alat pemadam kebakaran yang sesuai, yaitu dengan menggunakan semprotan air, uap atau busa (alcohol resistant foam), serta menginjeksikan karbon dioksisa. Apabila kasus kebakaran yang besar, maka segera lakukan evakuasi ke tempat yang aman karena tempat penyimpanan bisa meledak apabila terpanaskan. Apabila bereaksi dengan senyawa dengan jumlah yang banyak, seperti agen reduksi yang kuat, (sebagian) asam dan minyak / lemak, serta uap air senyawa basa akan menyebabkan potensi kebakaran/ledakan yang tinggi.

Saat terjadi tumpahan Asam Sulfat, maka alat pemadam kebakaran yang sesuai, yaitu Quick-acting ABC powder Extinguisher, Quick-acting BC powder extinguisher, Quick-acting CO2 extinguisher, Class $B$ foam (alcohol-resistant). Tidak diperkenankan menggunakan air untuk memadamkan api.

Saat terjadi tumpahan Solar, maka alat pemadam kebakaran yang sesuai, yaitu APAR untuk kategori B, bahan kimia kering, karbon dioksida, water spray, busa pemadam kebakaran dan agen gaseous lainnya. Apabila terjadi kebakaran besar, maka alat pemadam yang sesuai adalah Water spray, busa pemadam kebakaran.

\section{- Alat Pelindung Diri (APD)}

Alat Pelindung Diri (APD) yang sesuai untuk penanganan B3 nikel terdiri dari pakaian pelindung yang resistan terhadap bahan kimia, face-shield, sarung tangan, kacamata pelindung, jika ventilasi tidak memadai, maka diperlukan alat bantu pernafasan berupa masker gas. Material alat pelindung diri yang cocok untuk kontak adalah butyl-rubber dengan ketebalan $0,5 \mathrm{~mm}$.

Alat Pelindung Diri (APD) yang sesuai untuk penanganan B3 chromium trioxide meliputi safety glasses, sarung tangan, pakaian pelindung tahan korosi, apabila bahan berbentuk serbuk, maka diperlukan alat pelindung kepala/leher, serta alat bantu pernafasan dengan menggunakan masker gas tipe P2. Bahan pakaian dengan tingkat resistan tinggi : butyl rubber, PVC.

Alat Pelindung Diri (APD) yang sesuai untuk penanganan B3 asam sulfat meliputi sarung tangan, face shield, pakaian yang resistan terhadap bahan kimia, protective goggles, masker gas dengan tipe filter E. Bahan pakaian dengan tingkat resistan tinggi : butyl rubber, polyethylene, dan tetrafluoroethylene.

Alat Pelindung Diri (APD) yang sesuai untuk penanganan B3 solar meliputi sarung tangan, pelindung wajah, pakaian yang resistan terhadap bahan kima, protective goggles, masker gas dengan ketentuan A NIOSH/MSHA-Approved. Bahan pakaian: E.I DuPont TyChem, Saranex, atau bahan lain yang direkomendasikan sesuai dengan tingkat paparan; Bahan sarung tangan: nitrile, neoprene atau PVC.

\section{- Evakuasi}

Evakuasi karyawan di koordinir oleh koordinator gedung agar berjalan dengan tertib dan efektif, dilakukan melalui tangga darurat atau sarana prasarana lain. Hal-hal yang harus diperhatikan dalam hal evakuasi, yaitu melakukan jalan cepat, hindari berlari, melepaskan atau tidak membawa barang yang dapat mengganggu proses evakuasi, memprioritaskan karyawan lain yang rentan secara fisik, berjajar secara tertin Ketika menuruni tangga. Apabila terperangkap dalam asap, bernafas pendek melalui hidung, bergerak secara merangkak, dan gunakan masker asap apabila tersedia. Setelah keluar dari tangga darurat, kemudian langsung menuju tempat kumpul sementara. 


\section{- Prosedur Penyelamatan}

Prosedur penyelamatan di koordinir oleh koordinator pengamanan dokumen, hal yang wajib dilakukan saat penyelamatan dokumen, yaitu memilih dokumen berharga/penting untuk diselamatkan dan hanya membawa dokumen sesuai kemampuan agar tidak menghambat proses evakuasi.

Prosedur penyelamatan jiwa yang harus dilakukan adalah berikan pertolongan pertama apabila memungkinkan. Evakuasi korban menuju tempat yang aman melalui jalur evakuasi. Segera hubungi tenaga medis untuk tindakan lebih lanjut.

\section{- Prosedur Pemulihan Kedaruratan}

Dalam prosedur pemulihan kedaruratan, coordinator tanggap darurat melakukan pembentukan tim pemulihan keadaan darurat di PT. X. Pemulihan yang dilakukan terfokus pada sumber daya manusia, lingkungan, dokumen, dan infrastruktur. Apabila kondisi darurat telah teratasi, maka koordinator tanggap darurat mengevaluasi dengan mempertimbangkan hasil pemeriksaan pihak berwajib apakah lokasi kejadian telah aman. Tim pemulihan mendata seluruh korban serta kerugian yang ada serta membuat solusi agar kegiatan operasional dapat Kembali berlangsung. Tim pemulihan juga bertanggung jawab untuk membuat laporan ketikdak sesuaian untuk menjadi dasar tindakan perbaikan.

\section{KESIMPULAN}

Setelah dilakukan evaluasi dan analisis, komponen dalam sistem tanggap darurat terbagi dalam tiga bagian diantaranya manajemen tanggap darurat, sarana dan prasarana kedaruratan serta pengelolaan B3. Hasil rata-rata kesesuaian manajemen tanggap darurat di PT. X sebesar $16,67 \%$, sehingga diperlukan perbaikan manajemen tanggap darurat tumpahan B3 di PT. X untuk dijadikan prioritas utama dalam perbaikan dikarenakan hasil dari identifikasi B3 di PT. X memiliki potensi bahaya menengah. Nilai pada fasilitas saran dan prasarana didapatkan hasil sebesar $52,26 \%$, sehingga perlu dilakukan perbaikan terutama pada bagian-bagian seperti melengkapi alarm pada bagian produksi yang belum tersedia, isi kotak P3K, windsock, peralatan pengurung, agen penetralisir, dan bila memungkinkan penambahan pusat kontrol darurat. Untuk pengelolaan B3 di PT. X didapatkan hasil rata-rata dengan kesesuaian sebesar 80,54\%, untuk meningkatkan bagian tersebut perlu dilakukan perbaikan pada pemasangan symbol di tempat penyimpanan B3 chromium trioxide dan nikel untuk memberi rambu pada pekerja. Berdasarkan hal tersebut diperlukan perbaikan sistem tanggap darurat tumpahan B3 berupa rancangan RPK untuk mematangkan kesiapan perusahaan dalam menghadapi kondisi darurat yang dapat terjadi akibat dari B3 serta meminimalisir dampak dan kerugian secara material dan finansial yang terjadi.

\section{DAFTAR RUJUKAN}

American National Standard Institute (ANSI). (2005). "ANSI Z358. 1-2004 Emergency

Eyewash \& Shower Equipment-What You Need To Know". ASSE Professional Development

Conference and Exposition". American Society of Safety Engineers.

Hess Corporation . (2012). "Material Safety Data Sheet for Diesel Fuel".

Keputusan Menteri Tenaga Kerja R.I No. 187 Tahun 1999 Tentang Pengendalian Bahan

Kimia Berbahaya di Tempat Kerja

LabChem (2018). "Material Safety Data Sheet for Nickel". LabChem Inc : USA. 
LabChem (2018). "Material Safety Data Sheet for Sulfuric Acid". LabChem Inc : USA LabChem (2019). "Material Safety Data Sheet for Chromium Acid". LabChem Inc : USA.

National Fire Protection Association (NFPA). (2009). "NFPA 101 : National Fire Protection Association". Quincy, MA 2(1): 1-34.

National Fire Protection Association (NFPA). (2010). "NFPA 72: National Fire Alarm And Signaling Code". The Association.

National Fire Protection Association (NFPA). "NFPA 10: Provide One Fire Extinguisher At Each Stair On Each Floor Of Buildings Under Construction And Demolition".

Peraturan Menteri Tenaga Kerja dan Transmigrasi No. 08 Tahun 2010 Tentang Alat Pelindung Diri

Peraturan Menteri Tenaga Kerja dan Transmigrasi No. 15 Tahun 2008 Tentang Pertolongan Pertama pada Kecelakaan di Tempat Kerja

Peraturan Menteri Lingkungan Hidup dan Kehutanan Republik Indonesia Nomor 74 Tahun 2019 tentang Program Kedaruratan Pengelolaan B3 dan/atau Limbah B3

Safe Work Australia (SAW). (2012). "Guide For Major Hazard Facilities: Emergency Plans" Salami, I. R. S. (2015). "Kesehatan Dan Keselamatan Lingkungan Kerja". Gadjah Mada University Press. 